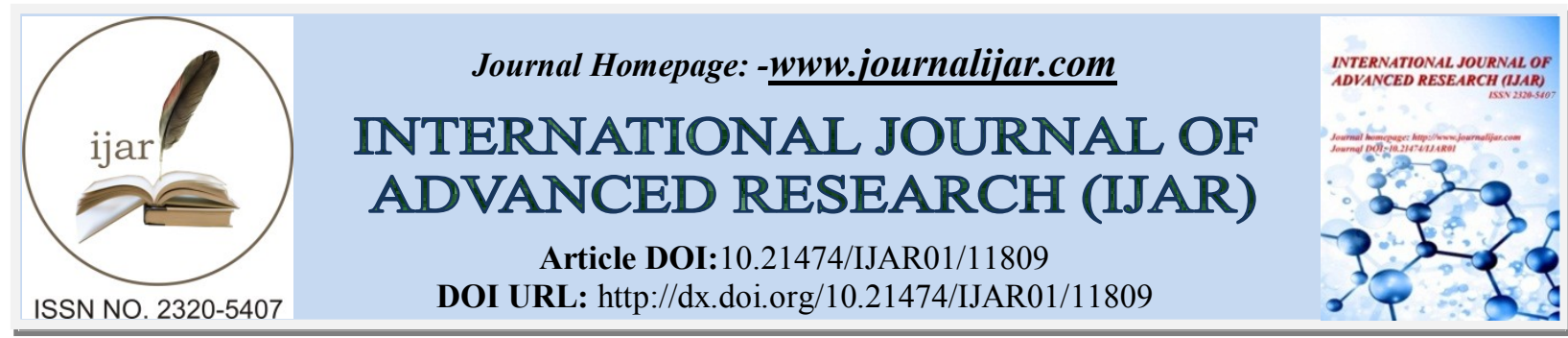

RESEARCH ARTICLE

\title{
COMPARISON STUDY BETWEEN ULTRASOUND AND SHORTWAVE AS A PHYSIOTHERAPY TREATMENT IN FROZEN SHOULDER CONDITION
}

\author{
Maad Al-Sadoon ${ }^{1}$, Showki Abdulameer Khudhair ${ }^{1}$, Majid Khamees Challoob ${ }^{2}$ and Fatimah Abbas Jumaah ${ }^{3}$ \\ 1. M.B.Ch.B., DR \& Med. Rehab. A Rheumatology Specialist. \\ 2. Chief Physical therapist senior, Physiotherapist at Physiotherapy Units/Al-Yarmouk Teaching Hospital. \\ 3. Physiotherapist, Physiotherapist at Physiotherapy Units/Al-Yarmouk Teaching Hospital.
}

\section{Manuscript Info}

Manuscript History

Received: 26 July 2020

Final Accepted: 31 August 2020

Published: September 2020

Key words:-

Adhesive Capsulitis, Physiotherapy,

Ultrasound, Shortwave, Stiffness

\section{Abstract}

Background: Frozen shoulder is a spontaneous onset condition, disabling and sometimes severely painful condition accompanied by progressive limitation of both active and passive movements of shoulder joint. It is one of the important conditions that could be treated by physiotherapy.

Methods: Patients attending day clinic department and physiotherapy units in AL-Yarmouk Teaching Hospital in Baghdad/Iraq. A prospective study covered 94 adult patients.

Results: Half (50.0\%) of the sample were in the old age group (56-70) year. Female more than male $(55.3 \%, 44.7 \%$ respectively), more than half of the patients $56.4 \%$ have right sided affected. There was no significant difference in the results between the two methods of treatment $(\mathrm{p}=0.512)$. The improvement rate $57.8 \%$ is higher among those with mild degree of stiffness, although there was no significant difference between the three degrees of stiffness $(p=0.185)$.

Conclusions: Frozen shoulder is a disabling condition and recovery needs a long-term process. Many physiotherapy options are available for the management, but there is still no consensus among the rheumatologist regarding which therapeutic option is superior. In this study both ultrasound and short-wave therapies have no difference in the outcome of frozen shoulder management.

Copy Right, IJAR, 2020,. All rights reserved.

\section{Introduction:-}

Frozen shoulder is one of the most poorly understood shoulder conditions. There is no specific definition for frozen shoulder, which is also known as adhesive capsulitis ${ }^{(1)}$. Yet Zuckerman and Rokito put a definition for frozen shoulder as "a condition of uncertain etiology, characterized by significant restriction of both active and passive shoulder motion that occurs in the absence of a known intrinsic shoulder disorder" ${ }^{(1)(2)}$. Codman identified the marked reduction in forward elevation and external rotation that are the hallmarks of the disease ${ }^{(3)}$.

The etiology of frozen shoulder is uncertain ${ }^{(3)}$. It is a spontaneous onset, disabling and sometimes severely painful condition accompanied by progressive limitation of both active and passive movements ${ }^{(4)}$. It has a natural history of spontaneous resolution and requires a management pathway that is completely different from other traumatic or pathological shoulder conditions ${ }^{(3)}$. 
The Estimated prevalence in the general population was 2-5\% ${ }^{(5)(6)(7)}$. Ogilvie-Harris et al. report an incidence of up to $3 \%$ in the general population ${ }^{(8)}$.Usual presentation of patients is in his sixth decade of life, onset before the age of 40 is very uncommon the peak age is 56 , and the condition occurs slightly more often in women than men ${ }^{(3)}$. The non-dominant shoulder is slightly more likely to be affected ${ }^{(3)}$.

The natural course for resolution takes 12-42 months. Fifteen percent of the patients experience long-term disability as a result of chronic loss of shoulder mobility ${ }^{(9)}$.

Frozen shoulder is one of the important conditions that could be treated by ultrasound \& shortwave physiotherapy (11).

Aim of the study:

The aim of this study was to determine whether there was a difference between short wave therapy and ultrasound therapy as methods of physiotherapy in the outcomes of frozen shoulder management.

\section{Patient And Method:-}

The study started from April to October 2019. The patients attending day clinic department and physiotherapy units at AL-Yarmouk Teaching Hospital in Baghdad/Iraq. A prospective study covered 94 adult patients.

Socio-demographic characteristics regarding age and sex was reported, in addition to full complaints of the patients and physical examination by a rheumatologist to assign the state of shoulder stiffness. In addition to information about associated chronic diseases.

Patients divided into two groups one group composed of 47 patients treated by short waves therapy (50-90 Hertis, continuous heads for seven minutes) with some muscle's exercises. The second group constituted of 47 patients too treated by ultra sound therapy (Pulsed $1.7 \mathrm{~W} / \mathrm{Cm}^{2}$ for 7 minutes) with same muscles exercise. Both groups were followed up to assess the response of the patients. According to the range of movement obtained by the treatment we classified the patients into three categories as following: Full range of movement as normal (Flexion 160-180 Abduction $170-180^{\circ}$ ) they were considered as "very good" response; range of movement $30-50^{\circ}$ degree less than normal were considered as "good" response. While range of movement $90-100^{\circ}$ degree less than normal were considered as "better" state from the starting point. Analgesics were used to control pain during physiotherapy sessions.

\section{Statistical issue:}

Data were grouped, tabulated and analyzed using SPSS v. 24 program. Frequencies and percentages calculated and Chi-square test was used to find the relationship between variables. P-value of 0.05 and less were considered as significant.

\section{Results:-}

Half $(50.0 \%)$ of the sample is in the old age group (56-70) year. Female more than male $(55.3 \%, 44.7 \%$ respectively), more than half of the patients $56.4 \%$ have right sided affected, Diabetes mellitus $27.7 \%$ was the highest prevalent chronic disease among the study group.

Table 1:- Some characteristics of the study patients.

\begin{tabular}{|l|l|l|l|}
\hline Variables & Frequency & Percent \\
\hline \multirow{5}{*}{ Age group } & $36-45$ & 20 & 21.3 \\
\cline { 2 - 4 } & $46-55$ & 27 & 28.7 \\
\cline { 2 - 4 } & $56-70$ & 47 & 50.0 \\
\hline \multirow{3}{*}{ Gender } & female & 52 & 55.3 \\
\cline { 2 - 4 } & male & 42 & 44.7 \\
\hline \multirow{2}{*}{ Side of stiffness } & left & 41 & 43.6 \\
\cline { 2 - 4 } & right & 53 & 56.4 \\
\hline \multirow{3}{*}{ Associated chronic diseases } & DM & 26 & 27.7 \\
\cline { 2 - 4 } & HT & 16 & 17.0 \\
\cline { 2 - 4 } & DM \& HT & 10 & 10.6 \\
\hline
\end{tabular}




\begin{tabular}{|l|l|l|l|}
\hline & None & 42 & 44.7 \\
\hline DM & & & \\
\hline
\end{tabular}

Table 2 showed the degree of response according to socio-demographic variables. The degrees of improvement were not significantly associated with age group, side, and associated chronic diseases but it was significantly associated with gender $(\mathrm{P}=0.04)$.

Table 2:- Response of patients to physiotherapy according to different variables.

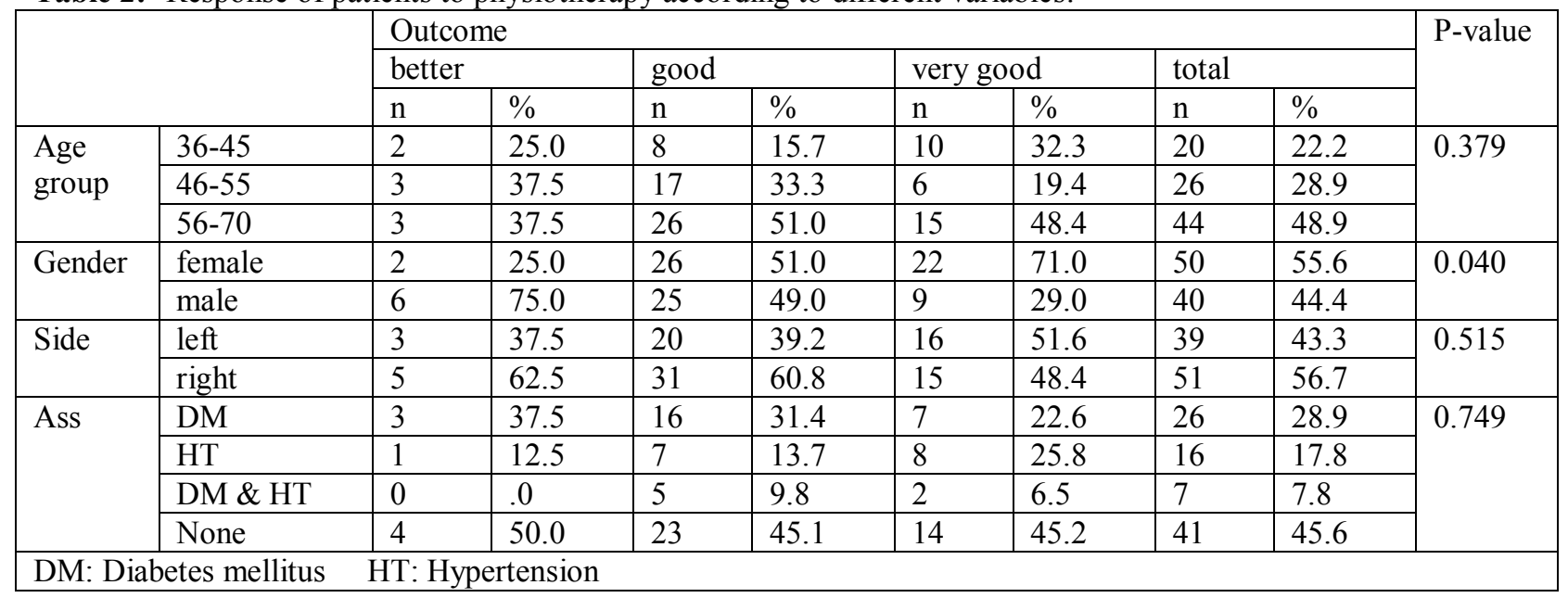

The degree of response of the patients to the two types of physiotherapy (short-wave and ultrasound) used in treatment were represented in (table 3). There was no significant difference between the two methods of treatment $(\mathrm{P}=0.512)$.

Table 3:- Outcome distributed according to type of physiotherapy machine used.

\begin{tabular}{|l|l|l|l|l|l|l|}
\hline \multicolumn{2}{|l|}{ Physiotherapy machine } & Outcome & P-value \\
\cline { 3 - 6 } \multicolumn{2}{|l|}{} & better & good & very good & total & \\
\hline & Short waves & $6(75)$ & $24(47.1)$ & $15(48.4)$ & $47(50.0)$ & \multirow{2}{*}{0.512} \\
\cline { 2 - 5 } & Ultra sound & $2(25)$ & $27(52.9)$ & $16(51.6)$ & $47(50.0)$ & \\
\hline Total & 8 & $51(100)$ & $31(100)$ & $94(100)$ & \\
\hline
\end{tabular}

Table- 4 revealed that the improvement rate $57.8 \%$ is higher among those with mild degree of stiffness, although there was no significant difference between the three degrees of stiffness $(p=0.185)$

Table 4:- Outcome distributed according to degree of stiffness.

\begin{tabular}{|c|c|c|c|c|c|}
\hline \multirow[t]{2}{*}{ Stiffness degree } & \multicolumn{4}{|c|}{ Outcome } & \multirow[t]{2}{*}{ P-value } \\
\hline & better & good & very good & total & \\
\hline mild & $4(50.0)$ & $34(66.7)$ & $14(45.2)$ & $52(57.8)$ & \multirow[t]{4}{*}{0.185} \\
\hline moderate & $1(12.5)$ & $7(13.7)$ & $10(32.3)$ & $18(20.0)$ & \\
\hline severe & $3(37.5)$ & $10(19.6)$ & $7(22.6)$ & $20(22.2)$ & \\
\hline Total & $8(100)$ & $51(100)$ & $31(100)$ & $90(100)$ & \\
\hline
\end{tabular}

\section{Discussion:-}

According to Russell et al. there is no agreement on the standard management of adhesive capsulitis, however he stated in 2014 that physiotherapy has shown relatively positive effects in short and long term ${ }^{(13)(14)}$. In another study Carrete et al showed that the multi-component intervention may be more effective than placebo injection at six weeks, but not at six or 12 months ${ }^{(13)}$.

Physical therapy and supervised home exercises, combined with pain management and intra-articular corticosteroid injections, are considered most important in the non-surgical treatment of frozen shoulder ${ }^{(10)}$. Gentle stretching exercises within the limits of pain can achieve greater mobility then aggressive stretching and strengthening ${ }^{(15)}$. 
Robertson and Baker reported the usage of ultrasound therapy in treating frozen shoulder. Both thermal and nonthermal effects of UST benefit in reducing inflammation and improve tissue extensibility ${ }^{(16)}$. Therapeutic ultrasound is frequently used in physiotherapy. Heating is the most important effect. Non-thermal effects are less understood and include molecular vibration, which increase cell membrane permeability and thereby enhances metabolic product transport ${ }^{(11)}$.

A positive significant decrease in shoulder joint pain in case of frozen shoulder at the end of four-week treatment program with short wave therapy was reported by Cacchio et al. ${ }^{(17)}$. These results may be clarified by the work of Lebrun ${ }^{(18)}$ It was evident that the extracorporeal shock wave therapy group demonstrated early improvements in pain reduction within four weeks as compared to the control group, which achieved similar pain reduction at 12th week $^{(19)}$.

The popularity of the deep heating agent using shock wave therapy has declined in recent years. This may be partly due to a shortage of quality-controlled studies, or because the SWD machine may cause radio-interference with other medical devices ${ }^{(5)}$.

In our study we found that the addition of deep heating: using ultra sound therapy to stretching exercises had no significant difference from adding short wave therapy to stretching exercises in the management of frozen shoulder.

\section{Conclusions:-}

Frozen shoulder is a disabling condition and recovery needs a long-term process. Many physiotherapy options are available for the management, but there is still no consensus among the rheumatologist regarding which therapeutic option is superior. In this study both ultrasound and short-wave therapy has no difference in the out come of frozen shoulder management.

\section{References:-}

1. Zuckerman JD, Rokito A. Frozen shoulder: a consensus definition. J Shoulder Elbow Surg. 2011; 20: 322-325

2. Chan HY, Pua PY, How CH. Physical therapy in the management of frozen shoulder. Singapore Med J. 2017; 58(12): 685-689

3. Dias R, Cutts S, Massoud S. Frozen shoulder (Clinical review). BMJ 2005;331:1453-56

4. Brue s, Valentin A, Forssblad M, Werner S, Mikkelsen C, Cerulli G. Idiopathic adhesive capsulitis of the shoulder: a review. Knee Surg Sports Traumatol Arthrosc. 2007;15:1048-54

5. Leung MSF, Cheing GLY, Effects of deep and superficial heating in the Management of frozen shoulder. J Rehabil Med 2008;40:145-50

6. Hannafin JA, Chiaia TA. Adhesive capsulitis: a treatment approach. Clin Orthop. 2000; 372:95-109

7. Ricci M, Castellarin G, Vecchini E, Sembenini P, Vangelista A. Adhesive capsulitis of the shoulder: arthroscopic and rehabilitative treatment. GIOT. 2004;30:60-64

8. Olgivie-Harris DJ, Biggs DJ, Fitsialos DP, MacKay M. The resistant frozen shoulder. Manipulation versus arthroscopic release. Clinical Orthopaedics and Related Research. 1995;319:238-48

9. Binder AI, Bulgen DY, Hazleman BL, Roberts S. Frozen shoulder: a long-term prospective study. Ann Rheum Dis. 1984;43:361-64.

10. van de Laar SM, van der Zwaal P. Management of the frozen shoulder. Orthopedic Research and Reviews 2014;6:81-90

11. Alarab A, Abu Shameh R, Shaheen H, Ahmad MS. Shock Wave Therapy and Ultrasound Therapy plus Exercises for Frozen Shoulder Joint Clients. Adv Nursing Patient Care Int J. 2018;1(2):180010.

12. Chen CY, Hu CC, Weng PW, et al.: Extracorporeal shockwave therapy improves short-term functional outcomes of shoulder adhesive capsulitis. J Shoulder Elbow Surg, 2014;23:1843-851.

13. Ebadi S, Forogh B, Fallah E, Ghazani AB. Does Ultrasound therapy add to the effects of exercise and mobilization in frozen shoulder? A pilot randomized double-blind clinical trial. Journal of Bodywork \& Movement Therapies. Accepted Nov. 2016. doi: 10.1016/j.jbmt.2016.11.013

14. Jason JI, Sundaram GS, Subramani VM.Physiotherpy intervension for adhesive capsulitis of shoulder: A systemic review. Int J Physiother Res 2015; 3(6):1318-25.

15. Vermeulen HM, Obermann WR, Burger BJ. End-range mobilization techniques in adhesive capsulitis of the shoulder joint: a multiple-subject case report. Phys Ther. 2000;80:1204-213. 
16. Robertson VJ, Baker KG. A review of therapeutic ultrasound: effectiveness studies. Phys Ther. 2001;81(7):1339-50.

17. Cacchio A, Paoloni M, Barile A, Don R, de Paulis F, Calvisi V, et al. Effectiveness of radial shock-wave therapy for calcific tendinitis of the shoulder: single-blind, randomized clinical study. Phys Ther. 2006;86(5):672-682.

18. Lebrun C. Understanding shock wave therapy for the treatment of bone and tendon pain Sportline. 2005;1(20):1-4.

19. Muthukrishnan R, Abdul Rashid A, Al-Alkharji F. The effectiveness of extracorporeal shockwave therapy for frozen shoulder in patients with diabetes: randomized control trial. J. Phys. Ther. Sci. 2019;31: 493-97. 